\title{
Reviewing peer review
}

One of the more deeply held tenets of biomedical research is that the quality of the scientific literature is only as good as the quality of the peer review that precedes publication.

Is this true? Will the tradition of peer review be lessened by the advent of electronic publishing and the

\section{Would quality be lost without peer review?}

possibility that rejected or eager authors will circumvent peer review by reporting data on "vanity" homepages? If authors did so in any numbers, would they be taken seriously? If peer review were to lose its preeminent place in scientific publishing, and as a corollary, as a measure of a researcher's status, would it matter? What is at stake?

Among the arguments against peer review that one often hears is that the physical scientists have all but given it up, yet the physical sciences are intellectually flourishing. Although there is some truth to the largely anecdotal information on this score, it may be more accurate to think of physicists marching down a parallel path to publishing. To be sure, before publication, data are often shared electronically among colleagues who are competent to evaluate each other's work. The electronic preprint is a staple. But journals in the physical sciences have yet to abandon peer review in print journals that form the archival record of new developments.

In the biological sciences and medical research, the circumstances are different and the risks greater. The complexity is without precedent. The language of each specialty is so particular to its own cell or organ system that researchers even in closely allied fields need translation. The likelihood that many biomedical scientists are able to evaluate work outside their own discipline(s) is nil. But the need to understand the basics of developments across the biomedical spectrum is as important now as it ever was.

Therefore, peer review must remain a vital part of biomedical science. Readers need the judgment of peers, but it does not necessarily follow that the peer review system must remain fixed in lead type.

The best way to decide if a manuscript is fair, a true advance, and probably accurate is to expose it to the constructive criticism of expert peer reviewers. Three terms in the previous sentence are particularly important to publication in a multidisciplinary journal (such as Nature Medicine). Although one author's view of a "true advance" may differ from another's, editors depend on peer review to help select papers that contain data or concepts that are more than me-too science. "Probably accurate" is also important. There is nothing to be gained by cluttering the literature with papers that may not hold up. On the other hand, sound, innovative but speculative work is what drives science. Editors and reviewers should be willing to take prudent risks. And, finally, peer review must be "constructive," not petty, if it is to be of real value to the scientific community.

This raises a question which, while not novel, is worth asking occasionally. Should peer review be anonymous? Certainly, the advent of electronic publishing, and with it the possibility of instant feedback, will create the equivalent of signed peer review - but after the fact.

In an ideal world, the idea of anonymous peer review would be an oxymoron. After all, tradition teaches that scientists are paragons of not only virtue but objectivity, ready at the drop of an editorial request to review a colleague's work with a view to making the science the best it can be. Indeed, peer review is a phenomenon based on a presumption of remarkable generosity that is often realized. Would it be even better if reviews were signed?

If you knew your name would appear at the end of published papers you reviewed, would it change for the better the quality of your review? Or would signed reviews be little more than polite pap? Arguments cut both ways. Science is a competitive game and much rides on publishing success. It might be too much to expect that, having endured an open review that resulted in rejection, authors could resist the temptation to reciprocate at the next opportunity. On the other hand, open review could bring out the best in people. As someone who has seen this happen in forums thrown open to public scrutiny by the Freedom of Information Act in the United States, I think this is not impossible.

But compulsory signed reviews could result in these responses by reviewers who are loath to offend: "Sorry, I can't review this," or "This manuscript is fine . . . I suggest you publish it." The first leaves the journal high and dry; the second is so uninformative as to be worthless.

During a recent event at Rockefeller University, a number of senior scientists declared themselves willing to sign reviews. Do they speak for others? Is this an experiment that, having been tried before, is worth trying again? Perhaps so, but we're not crazy enough to push the idea too far.

Please advise (medicine@naturedc.com).

- Barbara J. Culliton 